\title{
Políticas urbanas, territórios e exclusão social: as favelas nas grandes cidades - Brasil e Índia
}

\author{
MARIE-CAROLINE SAGLIO-YATZIMIRSKY
}

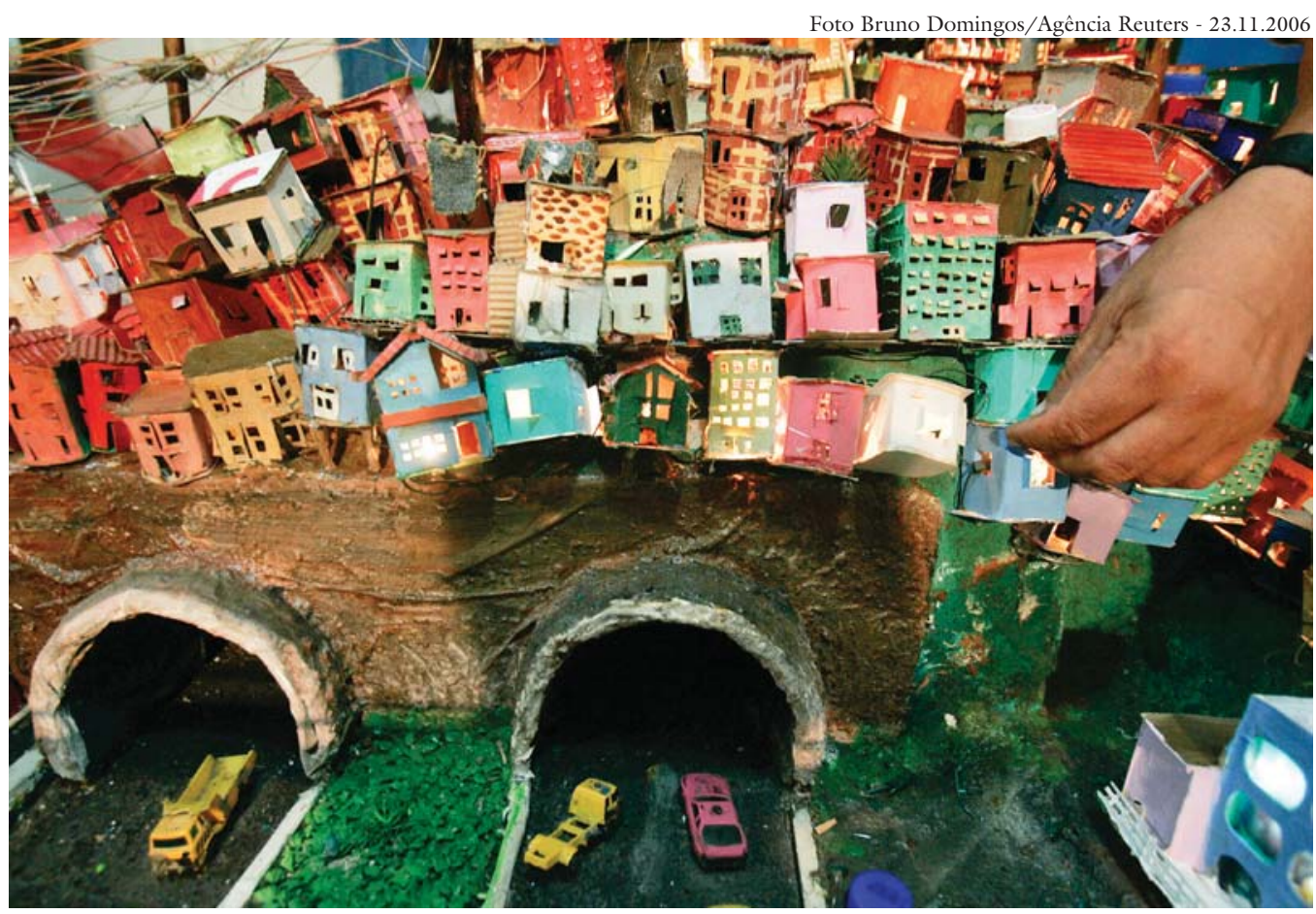

As esculturas de Tio Lino retratam paisagens da favela da Rocinba, no Rio de Janeiro (RJ).

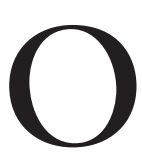
ESPETACULAR crescimento urbano das grandes metrópoles da Índia e do Brasil nos últimos 50 anos, assim como a reestruturação econômica realizada nesses países exerceram impactos comparáveis no que diz respeito à aceleração das desigualdades e da exclusão social. Essas dinâmicas se leem na reorganização do território urbano e na multiplicação dos conflitos entre os pobres e a população de renda média e alta, de um lado, e entre as zonas urbanizadas e as áreas de proteção ambiental, de outro.

Mumbai, capital econômica da Índia, que possui 12 milhões de habitantes (19 milhões habitantes em sua área metropolitana), bate o triste recorde mundial de ter $54 \%$ da sua população vivendo em slums, ou seja, áreas de moradia degradada e carente, nas quais os habitantes não possuem títulos legais de moradia. Delhi, com 13 milhões de habitantes (21 milhões em sua área metropolitana), 
segue com $19 \%$ da população vivendo em slums. As favelas são uma importante questão que se repete também nas maiores metrópoles do Brasil, compreendendo mais de $20 \%$ da população da municipalidade de Rio de Janeiro (6,2 milhões de habitantes e 11,3 para a sua área metropolitana) e, dependendo das estatísticas, de $11 \%$ a 19\% da população de São Paulo (10,6 milhões de habitantes e 18,8 milhões incluindo toda a sua área metropolitana).

Um dos principais desafios dessas cidades, imposto pelo crescimento urbano descontrolado e pelas mudanças econômicas que precipitaram mais trabalhadores na rede informal e precária de trabalho, é a multiplicação de ocupações precárias. No Brasil, o fenômeno de “invasão" e ocupação, com ênfase sobre a ilegalidade, predomina. Em Delhi e Mumbai, o slum se define tanto por sua precariedade e pobreza quanto pela ilegalidade.

Este dossiê ora publicado em ESTUDOS AVANÇADOS focaliza a questão da pobreza dentro das cidades, sejam as gigantescas e estrategicamente visíveis favelas - como as urbanizadas da Rocinha (Rio), de Dharavi (Mumbai), de Paraisópolis (São Paulo) -, sejam alguns "bolsões de pobreza”, objetos de projetos de urbanização ou que sofrem, ainda, o perigo iminente de remoção. Quais são as possibilidades de enfrentamento desse fenômeno pelas políticas publicas? Comparando as políticas urbanas, percebem-se as mesmas dinâmicas: as legislações urbanísticas e os interesses político-financeiros da elite explicam, em grande parte, a incapacidade de se desenvolverem políticas sociais e habitacionais adequadas.

Os atores públicos respondem com programas habitacionais, visando remover ou urbanizar as favelas. Tais programas são propostos como soluções, mas podem suscitar novos conflitos (por exemplo, a construção de um conjunto residencial sobre uma zona de invasão anterior). A concepção e a implementação desses projetos, por vezes muito diferentes da letra da lei, devem ser questionadas. Também as respostas da comunidade e o impacto final dessas políticas fazem parte da nossa investigação. A nossa hipótese é de que a implementação dessas políticas urbanas tem impactos comparáveis no que concerne à exclusão social, expressando, assim, novos conflitos entre os atores (públicos, privados, sociedade civil que compreende, aliás, diferentes atores envolvendo desde indivíduos de classes sociais altas até ONG, associações de moradores etc.), entre os espaços (centroperiferia) e entre funções sociais específicas (habitação/recursos "naturais").

O programa Setup, "exclusão social, territórios e políticas urbanas”, programa francês desenvolvido desde 2006 com financiamentos do CNRS (Agência Nacional de Pesquisa Francesa), apresenta os seguintes parceiros científicos: o Centro de Estudos da Índia (Ceias-Ehess), o Centre de Sciences Humaines (Delhi), a Universidade de São Paulo (Departamento de Geografia e Instituto de Estudos Avançados) e a Universidade Federal de Rio de Janeiro (núcleo Favela e Cidadania, Escola de Serviço Social). O programa reúne 20 pesquisadores entre franceses, brasileiros, indianos, especialistas das questões urbanas da Índia e do Brasil, de formações diversas (historiadores, juristas, urbanistas, geógrafos, 
sociólogos, demógrafos, economistas etc.), para discutir e comparar as políticas públicas nesses territórios urbanos e a questão da exclusão social. O subprojeto slum-favela do Setup concentra suas pesquisas nas duas principais políticas: a urbanização e a remoção das favelas. A questão central é analisar se esses programas contribuem para a integração social e habitacional dos pobres no território urbano ou, ao contrário, se reforçam a exclusão socioespacial dos pobres urbanos. Os trabalhos de campo realizados em equipe em Mumbai, Delhi, São Paulo e Rio de Janeiro fornecem elementos para ilustrar essa discussão.

Em agosto de 2008, nós, da equipe Setup, nos reuníamos pela terceira vez num seminário internacional para discutir nossas primeiras conclusões. Fomos mais uma vez acolhidos pelo Instituto dos Estudos Avançados (IEA) da USP para dois dias de intensos debates entre a nossa equipe e pesquisadores convidados da USP, da UFRJ, assim como estudantes dessas instituições. Como responsável e coordenadora científica do Setup, quero agradecer ao IEA, que colaborou para a realização desse seminário, ao diretor dessa instituição, César Alves, aos debatedores da USP e, enfim, ao professor Ignacy Sachs, cuje interesso pela comparação Índia-Brasil estimulou a realização desse projeto.

O presente dossiê apresenta o resultado das reflexões do Setup nesse seminário. Está organizado em ordem lógica, com uma contextualização histórica das políticas públicas no que se refere às favelas nas metrópoles de Mumbai e São Paulo (Marie-Charlotte Belle), seguido por uma reflexão sobre o sistema jurídico de regularização fundiária no Brasil (Rafael Soares Gonçalves). Seguem artigos sobre as políticas habitacionais, como a análise dos programas de urbanização de duas favelas do Rio de Janeiro a partir do questionamento central sobre o fenômeno de inclusão/exclusão urbana (Maria de Fátima Cabral Marques Gomes e Lenise Lima Fernandes). Mônica Virgínia de Souza se concentra nas políticas públicas tardias na periferia, ilustrando sua reflexão com o caso da favela Maravilha no distrito da Cidade Tiradentes (SP), onde remoções ainda são comuns. Finalmente, no que diz respeito ao caso indiano, segue o estudo sobre os programas de remoção e urbanização realizados em Delhi e Mumbai (Véronique Dupont e Marie-Caroline Saglio-Yatzimirsky), que permite continuar a dimensão comparativa da reflexão entre Brasil e Índia. Para encerrar este dossiê, Ana Fani Alessandri Carlos propõe uma visão crítica da produção do espaço urbano na metrópole de São Paulo hoje.

Marie-Caroline Saglio-Yatzimirsky é antropóloga, professora doutora no Instituto National des Langues et Civilisation Orientales (Inalco, Paris, França), pesquisadora no Centro de Estudos da Índia (Ceias, CNRS-Ehess, UMP 8564) e coordenadora do Programa "Social Exclusion, Territories, Urban Policies in India and Brasil" (Setup, ANR, 2006-2009). @ - marieyat@hotmail.com

Recebido em 18.5.2009 e aceito em 2.6.2009. 


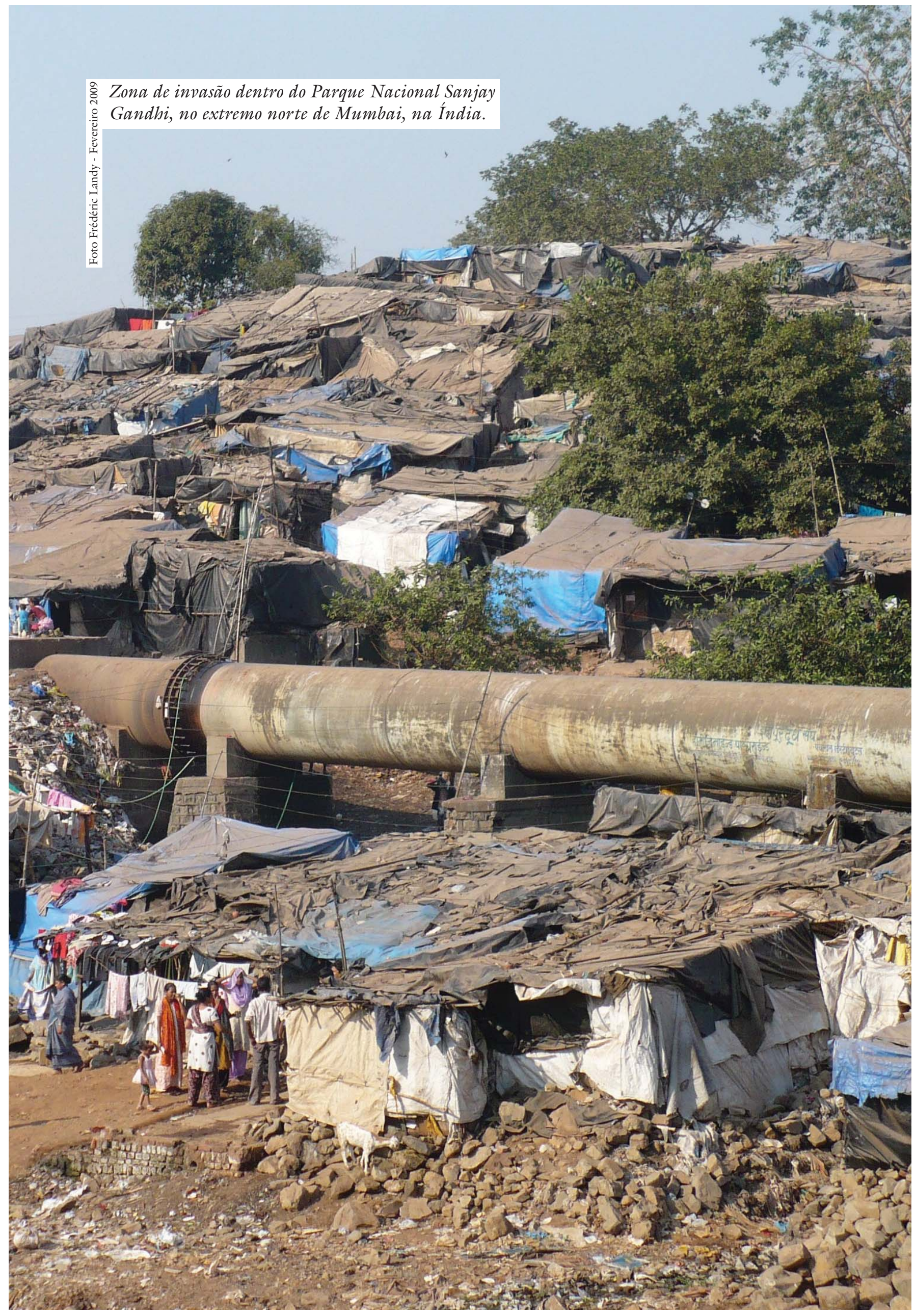

